\title{
2
}

\section{MAKNA RITUS DALAM TARI TOPENG CIREBON}

THEguH SAUMANTRI

Received: 7 Juli 2021; Accepted: 29 Agustus 2021; Published: 28 September 2021

Ed. 2021; 5 (1): 07 - 15

\begin{abstract}
The role of the mask has always been related to the socio-cultural life of a society. Mask art is a type of folk art. All people can dance mask art as a form to preservve and maintain the artistic heritage of their ancestors. The basis of this research is to reveal the meaning of a Cirebon mask dance symbol. In this research, the method used is descriptive qualitative as an effort to describe and analyze a phenomenon. From this research, it can be concluded that the Cirebon Mask Dance, which is a symbol of the manifestation (representation) of its supporting community, which is displayed in art performances is not just entertainment but has meaning, aesthetics, visual power, and dynamics of motion in its music.
\end{abstract}

Keywords: Rite, Mask Dance, Cirebon.

\section{PENDAHULUAN}

Di Cirebon dan sekitarnya, Penari Topeng dikenal dengan sebutan Dalang Topeng, kata Penari atau Tari, dalam bahasa Cirebon nyaris tak pernah dipakai dalam percakapan sehari-hari. Dalang Topeng adalah sebutan yang lazim digunakan untuk menunjuk Penari Topeng dan joged adalah kata yang artinya sama dengan tari. Kata Dalang tampaknya mempunyai makna untuk menunjuk status kegiatan seseorang yang berkaitan dengan keterampilan memainkan suatu kesenian.

Kesenian topeng ini merupakan jenis kesenian rakyat, jadi semua kalangan bisa menarikan kesenian topeng sebagai wujud untuk melestarikan dan mempertahankan warisan kesenian dari nenek moyang. Di Cirebon ada penari topeng yang bersifat keturunan dan penari topeng yang bersifat hiburan, tetapi kebanyakan penari topeng Cirebon berasal dari keluarga dalang (Maestro topeng Cirebon) yang diajarkan secaraturuntemurundalamkeluarganyasendiri.
Hidup seorang Penari Topeng adalah hidup yang penuh puasa dan pantang, puasa seninkamis adalah cara yang biasa mereka lakukan, dan sering tidur di makam-makam keramat. Inilah laku spiritual seorang Dalang Topeng, harus selalu mensucikan diri (meuseuh). Menjadi Dalang Topeng adalah sebuah pilihan hidup, ibaratnya seseorang yang memilih hidup sebagai "biarawan tari". Akibatnya mereka hanya mengenal satu cara hidup yakni menari topeng. Hidup mereka tergantung dari ada dan tidaknya permintaan masyarakat untuk menari (SurjaAtMadja, 1998).

Seseorang menjadi Dalang Topeng (zaman dahulu) dalam ritualnya selalu melakukan pembersihan diri (meuseuh diri, tapa brata) dengan berbagai laku astetiknya: puasa senin-kamis, puasa tujuh atau 40 hari, mutih, mati geni, kum, hanya makan sekepal nasi ketan, tidak makan nasi, dan lain-lain. Laku estetik tersebut ditujukan untuk mengembangkan kekuatan batin Dalang serta ketabahannya. 
Hal ini sejalan dengan apa yang dipaparkan oleh Nur Anani M. Irman S. Sen (Maestro topeng Cirebon gaya Losari), seorang Penari keturunan harus bisa menarikan semua jenis Tari Topeng dan menjalankan ritual yang telah diajarkan oleh nenek moyangnya, dengan melakukan puasa mutih, ngasrep, pati genti, ngayeb, wuwungan, ngrowot, mendem, nyepi, dan lainnya. (HASAN NAWi 1998).

Jika seorang Dalang Topeng itu "lulus", artinya berhasil melampaui ujian meuseuh diri, maka secara psikologis hal tersebut akan menimbulkan kepercayaan dan keyakinan dirinya diatas panggung. Meuseuh diri atau meditasi adalah sebuah perjalanan spiritual yang dilukiskan sebagai pondasi yang menjadi pijakan bangunan zikir dan mengingat Allah.

Selain menjalankan ritual, seorang Penari Topeng harus bisa menjiwai tariannya sesuai dengan perannya dalam karakter tari yang akan ditarikan, ketika menari penari merasakan keindahan dan kedekatan dirinya dengan Tuhan dalam jiwanya, jadi ada rasa jiwa itu menyatu dengan keindahan Tuhan bahwa Tuhan itu maha indah, sehingga menari bukan hanya untuk menghibur dan menunjukkan keerotisannya saja tetapi untuk mewujudkan keindahan Tuhan.

Berbeda dengan Penari Topeng yang bersifat hiburan, ia menari hanya sekedar menari saja dan jarang yang menjalankan ritual seperti Penari Topeng keturunan, ritual yang dijalankan Penari sanggar atau hiburan hanya untuk menjaga pakem saja. Dan pada umumnya mereka tidak mengetahui filosofi dari tarian itu, ia menari hanya sekedar hobi saja berbeda dengan Penari Topeng keturunan yang menjadikan tarian itu sebagai sesuatu yang sakral.

Penari Topeng hiburan tidak mempunyai pakem khusus yang mengatur untuk menjadi Penari seperti Penari Topeng keturunan yang harus melakukan meuseuh diri terlebih dahulu. Penari Topeng hiburan tidak harus menguasai semua jenis Tari Topeng, pada umumnya mereka hanya mengusai satu atau dua jenis tari topeng sesuai dengan apa yang mereka inginkan. Pada umumnya mereka menari untuk acara hiburan, pentas seni, dan mengikuti lomba-lomba tari. Busana yang dikenanakan sesuai dengan karakter gerakannya. (Wahyoe Koesoemah S. Sn., 2012).

\section{METODOLOGI PENELITIAN}

Penelitian ini digunakan metode analisis deskriptif dengan pendekatan kualitatif. Metode ini digunakan untuk mengkaji dan memahami makna yang ada dalam tari topeng cirebon. Menurut Creswell penelitian kualitatif adalah suatu proses penelitian ilmiah yang lebih dimaksudkan untuk memahami masalah-masalah manusia dalam konteks sosial dengan menciptakan gambaran menyeluruh dan kompleks. (MuHADJIR, 2000). Sehingga dalam penelitian ini didapati sebuah deskripsi, analis formal dan interpretasi tentang makna ritus dalam tari topeng cirebon.

\section{PEMBAHASAN}

\section{Tipologi Penari Topeng Cirebon}

Menurut Kamus Besar Bahasa Indonesia (KBBI) tipologi adalah ilmu watak tentang bagian manusia dalam golongan-golongan menurut sifat masing-masing. Tipologi Penari Topeng Cirebon dikelompokkan berdasarkan kesamaan ciri dan pengkhususan Penari secara umum yang diciptakan oleh masing-masing gaya daerah setempat. Persamaan cirinya dilihat dari penggunaan jenis-jenis kedok, prinsip menari, struktur tari dan ceritanya, sedangkan perbedaannya terletak pada gaya tari (gerakan), kostum, dan musiknya.

Penari Topeng Cirebon mempunyai dua tipologi, yaitu: Penari Topeng Cirebon wilayah barat dan wilayah timur, yang termasuk wilayah barat diantaranya yaitu penari topeng Cirebon gaya Slangit, gaya Gegesik dan gaya Palimanan, sedangkan yang termasuk kedalam wilayah timur yaitu penari Topeng Cirebon gaya Losari.

Penyertaan nama daerah di belakang kata topeng itu untuk mengetahui secara langsung 
tentang keberadaan topeng, gayanya (tari dan sistem penyajiannya), sosialisasi, dan persamaan-perbedaan aspeknya. Sebutan nama daerah di belakang kata Topeng menunjukkan kekhasan masing-masing pertunjukannya, karena perbedaan nuansa setiap Topeng itulah yang menyebabkan nama daerah di belakang kata Topeng itu disertakan. (Toto Amsar Suanda, 1989).

Penari Topeng Cirebon memiliki identitas yang berbeda dengan Penari Topeng lainnya, seperti Penari Topeng Cirebon gaya Losari (wilayah timur) dan Penari Topeng Cirebon gaya Gegesik, Slangit dan Palimanan (wilayah barat). Identitas Penari Topeng wilayah Timur lebih menjadikan Topeng itu sebagai doa atau ruwatan yang kaitannya untuk menyempurnakan diri dengan Tuhan, alam, dan bumi. Secara garis besar alam itu dilibatkan, berbeda dengan Penari Topeng Cirebon wilayah Barat yang lebih mengutamakan entertaint namun, bukan berarti Topeng Losari tidak bisa digunakan untuk acara entertaint, TopengLosaribisaditampilkandalam acara entertaint namun gerakannya tetap dipertahankan dan sudah menjadi pakem.

Perbedaan yang menonjol dari gaya daerah tersebut adalah susunan sajian tari. Susunan penyajian gaya topeng Slangit dimulai dari Panji, Pamindo, Rumyang, Tumenggung dan Klana. Tari Topeng gaya Slangit lahir di Slangit yang merupakan salah satu desa yang terletak disebelah barat Kabupaten Cirebon dan di desa tersebut banyak Dalang Topeng yang pada umumnya berasal dari keturunan. Salah satu Maestro Topeng gaya Slangit yang terkenal yaitu Sujana Arja. ("Bentuk Penyajian Pertunjukkan Topeng Cirebon,” n.d.).

Dalam gaya Gegesik, tarian panji jarang ditarikan karena koreografinya yang lebih banyak diam, tidak banyak gerak seperti orang yang mati tapi hidup, hidup tapi mati, hal tersebut yang menyebabkan Panji kurang disukai oleh penonton karena gerakannya yang terlalu halus.
Tari Topeng gaya Losari merupakan Tari Topeng Cirebon satu-satunya yang ada di wilayah Cirebon Timur, gaya Losari memiliki banyak perbedaan dengan Topeng yang lainnya. Dalam Tari Topeng gaya Losari terdapat Sembilan macam gerakan berikut lima lakonan yaitu Panji sutrawi-naugun, Patih jayabadra, Kil paduganata, Tumenggung magangdiraja, Jinggan anom, Klana, Bandopati, Rumyang dan lakonan. Dalam Topeng Losari Panji dijadikan urutan yang paling akhir karena dinyatakan tingkat ma'rifatnya yang tinggi sudah suci dan bersih. Keunikan dari Topeng gaya Losari adalah terdapat gerak galeyong atau kayang, yakni gerakan melilitkan badan ke belakang atau gerakan gantung sikil (gerakan menahan atau menggantung kaki yang cukup lama) dan gerakan naga seser (gerakan kuda-kuda). (HASAN NAWI, 1998).

Kostum yang digunakan Penari Topeng di wilayah Barat Cirebon (gaya Slangit, gaya Gegesik, dan Palimanan) dengan menggunakan kain bermotif mega mendung (batik khas Cirebon) sedangkan Penari Topeng di wilayah timur (gaya Losari) mengenakan kain bermotif liris atau parang yang merupakan motif khas Jawa Tengah karena lokasi Losari terletak di perbatasan antara Jawa Barat dan Jawa Tengah. (Hasan Nawi, 1998).

Macam-macam penyelenggaraan pertunjukkan topeng di Cirebon, yaitu :

1. AcaraKomunal,merupakanhajatanDesa atau kampung untuk kepentingan bersama sehingga hampir seluruh masyarakat terlibat dalam penyelenggaraannya. Penyelenggaraannya bermacam-macam dengan mengadakan sesaji, mengadakan pertunjukkan lebih dari satu kesenian, arak-arakan, permainan atau atraksi spektakuler yang dilaksanakan lebih dari satu malam.("Bentuk Penyajian Pertunjukkan Topeng Cirebon," n.d.).

2. Acara hajatan (topeng dinaan), istilah ini diperuntukkan bagi pertunjukan topeng yang penyajiannya dilaksanakan dalam acara kenduri misalnya, perkawinan, 
khitanan, dan sebagainya.

3. Acara barangan, merupakan jenis pertunjukan jalanan yang dibawakan oleh seniman keliling (wong bebarang) yang melakukan pertunjukan dimana saja menurutpermintaanorangyangmenanggap, sedangkan bentuk penyajiannya sesuai dengan banyaknya babak ,yang diminta. (Toto Amsar SuAnda, 1989).

\section{Ritual Penari Topeng Cirebon}

Ritual menurut KBBI (Kamus Besar Bahasa Indonesia) adalah sesuatu yang berkenan dengan ritus atau hal ihwal atau hal ihwal dengan ritus. Ritual merupakan suatu bentuk upacara atau perayaan yang berhubungan dengan beberapa kepercayaan atau agama dengan ditandai oleh sifat khusus, yang menimbulkan rasa hormat yang luhur dalam arti merupakan pengalaman suci. Pengalaman itu mencakup segala sesuatu yang dibuat atau dipergunakan oleh manusia untuk menyatakan hubungannya dengan "yang tertinggi", dan hubungan atau perjumpaan itu bukan sesuatu yang sifatnya biasa tetapi sesuatu yang bersifat khusus atau istimewa. (Y. Sumandiyo Hadi, 2006).

Dalam analisis Djamari mengatakan bahwa ritual bisa ditinjau dari dua segi yaitu tujuan atau makna dan cara. Jika kita melihat dari segi tujuan, ritual bertujuan sebagai rasa syukur kepada Tuhan dan ada juga yang bertujuan meminta ampun kepada Tuhan agara mendapatkan keselamatan dan rahmat dan ada tujuan meminta ampun atas kesalahan yang dilakukan. Tradisi jawa merupakan adat kebiasaan turun temurun dari nenek moyang yang masih dijalankan di masyarakat Jawa. (SANTI, 1999).

Peranan Topeng sejak dahulu terkait dengan kehidupan sosial budaya suatu masyarakat. Awalnya masyarakat menjadikannya sebagai sarana pemujaan kepada para leluhur. Kini mereka masih mempercayai akan adanya makhluk halus atau makhluk ghaib yang mendiami benda-benda atau tempat-tempat tertentu, seperti: makam-makam, sumur-sumur, sungai-sungai, benda-benda kuno dan sebagainya. Ke- beradaan makhluk-makhluk halus itu diyakini mempengaruhi psikologi kehidupan mereka. Pengaruh itu tidak saja menimbulkan rasa khawatir dan takut, akan tetapi juga rasa hormat dan syukur. Oleh karena itu, untuk mengatasi berbagai kondisi perasaan itu mereka mengimplementasikannya dengan berbagai ekspresi yang biasanya terbungkus dalam sebuah ritus. (Toto Amsar Suanda, 1989.)

Hj Juni dan Nani Sawitri dengan Tari Topengnya mempunyai pandangan untuk meneruskan warisan leluhurnya dalam rangka menjaga ikatan rohani bagi masyarakat tradisional, menjaga ikatan dengan alam ghaib (roh-roh halus) dan menjaga kelangsungan adat. Sistem keturunan dan kepercayaan kepada roh leluhur yang bisa datang untuk memberi kekuatan, masih merupakan tradisi kuat (walau kini tampak sedikit demi sedikit makin luntur). Banyak dalang topeng dan dalang wayang secara teratur menjalankan laku, seperi puasa, memuja leluhur dan sebagainya.

Dalam pertunjukan Tari Topeng Cirebon, ada ritual khusus yang dijalankan oleh Para Penarinya sebelum maupun sesudah pertunjukkan Tari Topeng berlangsung. Sebelum menari, Penari Topeng melakukan Manji terlebih dahulu dengan menghadap ke kotak atau yang biasa dikenal dengan pengabaran. Manji merupakan singkatan dari Mapang ing ka sawiji. Maksudnya adalah kalau kita melakukan sesuatu harus menghadap ke Tuhan Yang Maha Esa terlebih dahulu, Allah itu dihadirkan didalam tubuh dengan menyebut asma-Nya. Jadi ketika menari itu hakikatnya berdzikir atau berdoa.

Pengabaran merupakan sebuah mantra yang dibacakan secara khusus supaya Penari tetap laris atau laku. Mantra yang dibacakan yaitu "Dramawinangun teka tika ing kang sulung. Dramawinangun berarti membangun krama atau cinta. Teka tika ing kang sulung berarti supaya datang dan sang penari diberi penerangan atau diberi cinta dengan cinta, sang Penari bisa memahami. Sifat sakral tarian ini ditujukan oleh para Dalang Topeng yang akan memper- 
tunjukkan tarian-tariannya. Sebelum seorang Penari menarikan Panji, ia mengucapkan mantra di depan kotak penyimpanan kedok-kedok. Mantra Ini hanya diberikan oleh guru kepada muridnya dan untuk orang lain adalah hal yang tabu. Toto Amsar Suanda berhasil memperoleh sebagian mantra tersebut yang berbunyi:

\section{Sumerah maring Allah \\ Sakapindo maring Rasulullah \\ Kang anane ning wetan \\ Sinubun Gunung Jati \\ Kang sume kang ana Gunung Jati \\ Nyi Rengge Asmara \\ Kang anama Sang Hyang Permana \\ Kang ana ing kulon \\ Sang tunggul putih \\ Kang anama Kesamadtullah \\ Kula titip pandita 40 \\ Kang asih nikmat ning badan \\ Kula titip maring Abdul Muthalib \\ Cuan lamun ora dijaga bending \\ Kenang bendungane Allah Ta'ala \\ Allahuma bisrokhman \\ Mil suci saking umat \\ Kanjeng Nabi Mubammad \\ Allabumma sotiamin \\ Nyuwun ning Pangeran Bonang \\ Pangeran Panggung minta diraksa \\ Sajabane sajerone panggung.}

(Toto Amsar Suanda 1989).

Makna dari mantra tersebut adalah untuk membantu daya tahan dan kekuatan penari dalam menarikan tari-tariannya yang banyak itu, dan berlangsung satu hari penuh. Kenyataannya mereka mampu menari sepanjang hari, bahkan ketika baru saja menderita sakit juga ada yang mampu menari sambil "tidur" di pentas (diluar kesadaran). (SuryaAtMadja, 1980).

Penari Topeng keturunan harus bisa melakukan ritual sesuai dengan apa yang diajarkan oleh nenek moyang, Ada berbagai macam ritual yang dijalankan oleh Penari Topeng Cirebon, yaitu berupa ritual fisik dan ritual batin. Ritual fisik merupakan rutinitas ritual yang dijalankan setiap malam jum'at dan pada waktu-waktu tertentu dalam kepercayaan Jawa (kejawen). (SurjaAtMadja, 1998).

Pentingnya hari Jum'at tampaknya berasal dari tradisi Islam yang menganggap Jum'at sebagai hari paling utama utuk mengerjakan perintah agama. Tradisi sastra setempat menyebutkan bahwa Jum'at kliwon secara tradisional dipakai oleh Sunan Gunung Jati sebagai hari pertemuan Istana, karena jum'at kliwon adalah hari yang baik untuk mengetahui baik buruknya maksud seseorang (bisa niteni ala becike niyate wong). (Dr. Muhaimin AG, 2001).

Ritual mingguan dijalankan setiap malam jum'at dengan memberi makan benda-benda kuno seperti topeng, keris, gamelan dan sebagainya. Ritual tersebut dijalankan di suatu ruangan yang khusus dan tidak boleh terkena cahaya (kondisi gelap total) Tetapi proses ritual yang dijalankan sangat privat tidak sembarang orang bisa mengetahui proses ritualnya, hanya dikhususkan untuk orang keturunan saja karena untuk menjaga pakem dan pesan dari nenek moyang. Ritual tahunan yang dijalankan yaitu berupa pencucian gamelan, keris, dan topeng. Waktu menjalankan ritual ini dilaksanakan pada waktu mulud, jam dan waktunya sama seperti ritual-ritual yang dijalankan di Keraton Cirebon, Yogyakarta, maupun Solo.

Dalam memperlakukan kedok-kedok (topeng) tidak dapat disimpan secara sembarangan. Kedok-kedok (topeng) harus selalu terbungkus dengan kain putih. Putih adalah warna Dunia Atas sejak masa Purbakala di Indonesia. Nilai kedok bukan pada segi estetiknya, tetapi lebih pada nilai magisnya. Seorang Penari Topeng Cirebon lebih memilih kedok (topeng) yang turun temurun telah dipakai menari, daripada kedok (topeng) baru. (LAKSMIWATI, 2013).

Gamelan yang digunakan untuk mengiringi Tari Topeng adalah gamelan yang berlaras Prawa dan berlaras Pelog. Adapun jenis Gamelan yang digunakan yaitu: 
1. Saron atau disebut juga penurut, artinya kita harus menurut kepada yang benar. Saron dua atau penimbal artinya setelah kita menerima kebenaran, kita harus menggetok tularkan kepada yang lainnya.

2. Bonang, artinya jangan sewenangwenang.

3. Kendang, jumlahnya ada 4 buah (yang besar 2 dan yang kecil 2). Bilangan 4 tersebut diartikan pada gerakan pokok orang yang sedang Shalat, yaitu: berdiri, ruku, sujud dan duduk.

4. Engklong, artinya adalah jangan goyah.

5. Gong, jumlahnya ada 2 buah, yang besar bernama Gong Gede dan yang kecil bernama Kiwul. Kiwul artinya kita jangan mudah terombang-ambing. Arti Gong Gede adalah sebagai manusia kita jangan merasa gumede (besar kepala). Kiwul (Gong Kecil) berbunyi "Gung", sedangkan Gong Gede berbunyi "Ger". Artinya kita harus menyembah kepada yang Agung (Allah SWT) yang angger (tetap). (HASAN NAWI 1998).

Ritual batin yang dijalankan oleh Penari topeng Cirebon salah satunya adalah dengan menjalankan puasa, ritual puasa yang dilakukan berbeda dengan puasa pada umumnya. Puasa bagi kalangan Penari Topeng ini sangat berat bagi orang pada umumnya, tetapi bagi kalangan Penari Topeng Cirebon dengan keyakinan penuh mereka mampu melakukan ritual puasa tersebut. Ada 4 macam puasa dalam ritual batin yang dijalankan oleh penari Topeng Cirebon, diantaranya:

1. Puasa Mutih, puasa ini berasal dari kepercayaan Jawa. Dilakukan dengan menahan makan dan minum kecuali yang putih-putih, hanya boleh makan nasi putih dan tidak boleh disertai lauk pauk, minumnya hanya dengan air putih. Dilakukan mulai tengah malam hingga malam hari berikutnya.

2. Puasa Ngidang, yaitu hanya makan dedaunan saja dengan tangan diikat di bamboo kuning bila makan harus meng- gunakan mulutnya dan tidak boleh makan dengan menggunakan tangan atau kaki.

3. Puasa Ngasrep, yaitu hanya boleh minum air putih dingin tanpa dicampuri apapun dan makan makanan yang dingin.

4. Puasa Ngrowot, yaitu menjalani laku keprihatinan dengan tidak memakan nasi, sebagai gantinya, ubi-ubian terutama jagung, ubi kayu, ubi jalar, tales-talesan menjadi menu utama hidangan. (Dr. Muhaimin, AG 2001).

Realitas ini merupakan wujud ekspresi Masyarakat Cirebon umumnya dan khususnya Penari Topeng Cirebon dalam melestarikan tradisi ritual yang rutin dilakukan setiap tahunnya. Peristiwa budaya seperti ini sangat erat kaitannya dengan tokoh-tokoh legendaris Cirebon yang telah berjasa dan memiliki popularitas serta menjadi panutan bagi masyarakat Cirebon.

Ketahuilah misalnya, Alm Dewi dan Sawitri Maestro Topeng Cirebon gaya Losari, Alm Suteja, Suparta, Sujaya, Sujana, dalang Topeng asal Slangit, dan Rasinah dari pekandangan, Indramayu. Pada umumnya mereka menceritakan hal yang sama tentang bagaimana pengalaman mencapai profesi sebagai Dalang Topeng, puasa senin-kamis, mati geni, hanya makan nasi sekepal tidak makan nasi untuk sekian lamanya, tidur di makam yang dikeramatkan (buyut) dan sebagainya. Adalah pengorbanan hidup yang harus dilewati dan hal itu nampaknya bagian kehidupan yang harus dilakoninya. (Toto Amsar SuAnda, 1989).

\section{Makna Ritual Tari Topeng Cirebon}

Pemakaian Topeng dimaksudkan untuk menyembunyikan identifikasi pemakainya agar tidak dikenal oleh peserta upacara, karena pemakaian topeng hanyalah "benda hidup" yang menjadi perantara dunia roh dengan manusia. Pemakaian Topeng juga cenderung menunduk, bukan menatap langsung ke depan agar roh yang memasuki Topeng tidak memasuki diri pemakainya. Antara Penari dan Topeng harus bisa menyatu, kedok harus menghidup- 
kan tarian dan tarian harus menghidupkan kedok tersebut.(Yayasan Budaya Sunyaragi 1988)

Nur Anani (Maestro Topeng Losari) memiliki kedok kuno yang berjumlah 80 kedok yang sudah berumur ratusan tahun, kedok tersebut dibuat ketika Pangeran Losari membuat Kereta Singa Barong, kurang lebih umurnya mencapai 380 tahun. Meskipun sudah rusak tet,api memiliki auranya berbeda.(HASAN NAwI 1998)

Dalam pertunjukkan Topeng, kotak Topeng difungsikan untuk menyimpan beberapa perlengkapan pertunjukkan antara lain kedok-kedok yang akan ditarikan, kostum, alat tabuh gamelan dan lainnya. Kotak tersebut diletakkan di tengah-tengah panggung dan bermakna sebagai simbol tentang asal usul kehidupan manusia. Kotak Topeng juga bermakna sebagai pusat pamiangan dan pangbalikan (pergi dan pulang). Itulah mengapa penari topeng selalu mulai menari di dari depan kotak (manji) dan berakhir di depan kotak pula. (Toto Amsar Suanda, 1989)

Kesadaran menjalankan ritual pada dasarnya adalah suatu tindakan untuk mempertemukan kesadaran religious dan kesadaran mitos. Pencucian dan pemberian makan kepada benda kuno (mupuk) dimaksudkan sebagai media penghormatan kepada leluhur yang menciptakan kesenian topeng dan sebagai upaya untuk mengeluarkan energi yang lama dan menggantinya dengan energy yang baru. Ritual sebagai upaya manusia dengan melibatkan Allah dalam setiap pekerjaannya. (Genik Puji Yuhanda, 2017).

Makna dari ritual yang dijalankan yaitu untuk memperoleh keselamatan ketika menari supaya tidak mendapatkan gangguan-gangguan negatif selama di panggung maupun dalam kehidupan sehari-hari. Selain itu untuk memperoleh perlindungan ketentraman hidup, kebahagaiaan, dan kesehatan dari Allah SWT supaya tidak ada halangan untuk tetap menari. Ritual juga dimaksudkan untuk memenuhi adat istiadat yang telah dijalankan oleh para leluhur supaya tetap mempertahankan pakem ritualnya dan juga sebagai bukti rasa terimakasih kepada Tuhan Yang Maha Esa dan para leluhur. (Sumardjo, 2000).

Ritual juga menjadikan diri kita semakin ikhlas (menep) ketika menari jadi menarinya enak tanpa memikirkan yang lainnya sudah ikhlas lillahi ta'ala. Karena pada hakikatnya menari itu adalah sebuah mendoakan sebagai upaya untuk mendekatkan diri kita dengan Allah SWT.

Puasa dimaksudkan untuk mengosongkan diri, jika diri kita "kosong" akan mudah diisi apapun baik oleh pengetahuan lahiriah ataupun oleh kekuatan spiritual. Pengosongan badan ini berarti juga "pembersihan", dan ruh yang baik akan menyenangi diri yang bersih."kosong" berarti relaks dan menjadi kuat karena spiritual yang diminta jauh lebih kuat dari kekuatan diri yang dimiliki secara normal. (Dedeh Nur Hamidah, 2011).

Ritual batin yang dijalankan oleh penari topeng Cirebon dimaksudkan untuk melatih penari agar memiliki sifat prihatin dan melatih batin supaya tetap tenang, konsentrasinya lebih penuh, menarinya lebih ikhlas tanpa memikirkan apapun (menep), dan untuk mempertahankan stamina kondisi badan dan jiwa supaya tetap terjaga agar tidak mendapatkan halangan ataupun hambatan ketika menari.

Menurut DurKheIM, ada satu hal yang selalu ada dalam segala macam gagasan dan perilaku keagamaan makhluk manusia, yaitu perasaan sentiment bahwa hal-hal yang bersangkutan dengan religi atau agama itu bersifat keramat (sacred), berbeda dengan hal-hal yang tidak bersangkutan dengan religi at agama, yaitu yang bersifat profan. Manusia sebagai warga masyarakat masih tetap membutuhkan keyakinan-keyakinan, sentiment-sentimen, dan kesadaran kolektif yang memberikan identititas kepadanya dan yang memperkuat kebutuhan moralnya. Hal-hal ini sebaliknya memerlukan upacara-upacara yang ditentukan oleh gagasan-gagasan kolektif yang tidak pernah 
akan hilang dari kehidupan masyarakat manusia. (Koentjaraningrat, 1993).

Nuansa ritus dalam pertunjukan Topeng Cirebon tidak saja hanya dirasakan dalam upacara ritual (sakral), akan tetapi juga dapat dirasakan dalam acara pertunjukan yang bersifat profan seperti dalam acara hajatan perkawinan, khitanan, dan lainnya. Dengan demikian, secara umum, pertunjukan topeng itu sebenarnya mengandung makna mistis secara khusus dapat dirasakan pada topeng Panji yang gerakannya lebih banyak diam tetapi kaya akan filosofi, berbeda dengan ketika menarikan topeng lainnya. Keceriaan, kegesitan, dan kemeriahan akan tampak pada saat dalang topeng menarikan topeng Samba, Rumyang, Tumenggung, dan Klana. (SuryaAtMadja, 1980).

Pertunjukkan Topeng Cirebon di kalangan masyarakat diselenggarakan dalam fungsi yang berbeda, yaitu dari sifatnya yang sakral (keagamaan) dan profan (keduniawian). Dalam upacara ritual dan pelaksanaan keagamaan, Tari Topeng Cirebon berfungsi sebagai simbol perwujudan (representasi) komunitas pendukungnya sebagai upaya pertunjukkan seni, Topeng Cirebon ditampilkan sebagai seni hiburan karena estetika, kekuatan visual, dan dinamika gerak serta musiknya. Tidak heran jika topeng Cirebon menjadi primadona dalam penyelenggaraan festival atau pertunjukkan seni karena pesona atraktif yang dimilikinya.

Penari Topeng Cirebon menunjukkan rasa estetis atau keindahan dihadapan Tuhan, aspek estetis bisa muncul di alam, seni, menusia, laut, dan lainnya. Estetis dalam alam, seni, laut dan lainnya merupakan panggung keindahan warna warni ketuhanan yang serasi. Dalam konteks ekologi mengapa alam sudah rusak karena tidak lagi memperlihatkan sisi-sisi keindahan Tuhan sehingga alam menjadi begitu ganas, gersang, dan kering karena tidak memperlihatkan soal estetis. Secara tidak langsung, penari topeng Cirebon mengajak semua komponen manusia dari rakyat sampai pejabat agar memiliki aspek estetika dalam se- tiap pergaulan didalam kehidupan agar tidak muncul lagi sikap kekerasan atau radikalisme. (Genik Puji Yuhanda, 2017).

\section{KESIMPULAN}

Tari topeng atau kesenian menjadi budaya lokal di daerah cirebon. Kesenian topeng ini merupakan jenis kesenian rakyat, jadi semua kalangan bisa menarikan kesenian topeng sebagai wujud untuk melestarikan dan mempertahankan warisan kesenian dari nenek moyang. Dalam kesenian tari topeng, penari Topeng dikenal dengan sebutan Dalang Topeng, Dalang Topeng adalah sebutan yang lazim digunakan untuk menunjuk Penari Topeng dan joged adalah kata yang artinya sama dengan tari. Dalam kata Dalang mempunyai makna untuk menunjuk status kegiatan seseorang yang berkaitan dengan keterampilan memainkan suatu kesenian. Penari Topeng Cirebon mempunyai dua tipologi, yaitu: Penari Topeng Cirebon wilayah barat dan wilayah timur, yang termasuk wilayah barat diantaranya yaitu penari topeng Cirebon gaya Slangit, gaya Gegesik dan gaya Palimanan, sedangkan yang termasuk kedalam wilayah timur yaitu Penari Topeng Cirebon gaya Losari. Makna dari ritual dalam tari topeng yaitu untuk memperoleh keselamatan ketika menari supaya tidak mendapatkan gangguan-gangguan negatif selama di panggung maupun dalam kehidupan sehari-hari. Selain itu untuk memperoleh perlindungan ketentraman hidup, kebahagaiaan, dan kesehatan dari Allah SW'T supaya tidak ada halangan untuk tetap menari. Ritual juga dimaksudkan untuk memenuhiadat istiadat yang telah dijalankan oleh para leluhur supaya tetap mempertahankan pakem ritualnya dan juga sebagai bukti rasa terimakasih kepada Tuhan Yang Maha Esa dan para leluhur.

\section{DAFTAR PUSTAKA}

"Bentuk Penyajian Pertunjukkan Topeng Cirebon." n.d. http:disporbudpar.cirebonk ota. go.id/2015/10/26/bentuk-penyajian-pertunjukkan-topeng-cirebon/. 
Nur Hamidah, Dedeh.

2011. "Pengarub Tarekat Pada Topeng Cirebon." Holistik 12 (02).

Dr. Muhaimin AG.

2001. Islam Dalam Bingkai Budaya Lokal Potret Dari Cirebon. Jakarta:

PT Logos Wacana Ilmu.

Puji Yuhanda, Genik.

2017. "PESAN DALAM TARLAN TO

PENG PANJI CIREBON.”

Komversal : Jurnal Komunikasi

Universal 2 (2).

Nawi, Hasan.

1998. "Topeng Cirebon Arti Dan Maknanya." Cirebon.

KoEntJARANINGRAT.

1993. Ritus Peralihan Di Indonesia. Jakarta: Balai Pustaka.

Laksmiwati, Dyah Komala.

2013. Sintren: Keindahan Seni Budaya Cirebon. Cirebon: Rumah Budaya Nusantara Pesambangan Jati Cirebon.

Muhadjir, Noeng.

2000. Metodologi Penelitian Kualitatif.

Yogyakarta: Rake Sarasin.

Santi, Kartika Jamilah.

1999. Makna Topeng Panji Gaya Slangit Dalam

Topeng Cirebon. Bandung: Sekolah

Tinggi Seni Indonesia.

SumARDJO, JAKOB.

2000. Filsafat Seni. Bandung: ITB.

SurjaAtmadja, R. I. Maman.

1998. Tari Topeng Cirebon Dan Peranannya Di Masyarakat. Bandung: STSI Press.

SuryaAtMadja, MAMAN.

1980. "Topeng Cirebon Dalam Perkem

bangan Penyebaran Serta

Peranannya Dalam Masyarakat Jawa
Barat, Khususnya Di Daerah

Cirebon.”Bandung.

Amsar Suanda, Toto.

1989. Tari Topeng Panji Sebagai Tari Meditasi.

Bandung: Akademi Seni Tari

Indonesia.

Koesoemah S. Sn., Wahyoe.

2012. "Sinopsis Kesenian Tradisional Cirebon." Cirebon.

HADi, Y. SumANDiYO.

2006. Seni Dalam Ritual Agama.

Yogyakarta: Pustaka.

Yayasan Budaya Sunyaragi.

1988. Cirebon Cultural Exhibition on Batik, Mask, and Glass Painting. Cirebon: Yayasan Budaya Sunyaragi. 